\title{
REPRODUCTIVE FACTOR AND THE RISK OF BREAST CANCER AMONG WOMEN ATTENDING TERTIARY CARE HOSPITAL: A CASE CONTROL STUDY
}

\author{
Kannan Krishnamoorthy ${ }^{1}$, Gopal Rao Jogdand ${ }^{2}$, Yennam Naresh ${ }^{3}$
}

\section{HOW TO CITE THIS ARTICLE:}

Kannan Krishnamoorthy, Gopal Rao Jogdand, Yennam Naresh. "Reproductive Factor and the Risk of Breast Cancer among Women attending Tertiary Care Hospital: A Case Control Study". Journal of Evolution of Medical and Dental Sciences 2014; Vol. 3, Issue 12, March 24; Page: 3069-3075, DOI: 10.14260/jemds/2014/2245

\begin{abstract}
Breast cancer is predominantly a disease of women and has a major impact on the health of women. In India, the number of deaths due to breast cancer in the country has increased to 50, 821 in 2010 from 48, 170 in 2007. The present study was undertaken to identify risk factors for breast cancer in rural setting at Sushruta Cancer Institute, Karimnagar, Andhra Pradesh. METHODOLOGY: A hospital based case control study was conducted during the period of November 2010 to October 2012, with the sample of 300, out of 100 newly diagnosed breast cancer cases and 200 healthy controls. Cases and controls were matched with the age interval of 5 years. Information about the exposure were obtained in precisely manner both for cases and controls by using semi structured, pre tested questionnaire with the interview method along with clinical examination. RESULTS: Out of total 100 cases and 200 controls, about $29 \%$ of cases and controls were in the age group of 50-54 years and about $80 \%$ of study subjects were resident of rural area, $81.6 \%$ of the study population were Hindus. Occupation wise $60 \%$ were engaged with daily wages and about $76.7 \%$ were illiterates. It was observed that $80 \%$ of the study population belonged to Socio economic class IV \& V. The risk of developing breast cancer was statistically significant for the factors like marital status, parity, age at menarche and breastfeeding. CONCLUSION: The present study was an attempt to identify risk factors and to quantify the strength of their association so as to help eliminate gaps in knowledge and barriers regarding risk factors for breast cancer and to know which risk factors are important, feasible to tackle and preventable which would have a great potential as a primary prevention measure.
\end{abstract}

KEYWORDS: breast cancer, reproductive factors.

INTRODUCTION: Breast cancer is a malignant proliferation of epithelial cells lining the ducts or lobules of the breast. Cancer originating from duct is known as ductal carcinoma and those originating from lobules are known as lobular carcinoma. ${ }^{1}$

\section{MAGNITUDE OF BREAST CANCER PROBLEM:}

GLOBAL SITUATION: Breast cancer is predominantly a disease of women and has a major impact on the health of women ${ }^{2}$.Globally, breast cancer is by far the most frequent cancer among women with an estimated 1.38 million new cases diagnosed in $2008(23 \%$ of all cancers). It is now the most common cancer both in developed and developing regions with around 690, 000 new cases estimated in each region.

Incidence rates vary from 19.3 per 100, 000 women in Eastern Africa to 89.7 per 100, 000 women in Western Europe and are high (greater than 80/100, 000) in developed region of the world (except Japan), and low(less than 40/100, 000) in most of the developing regions. 
The range of mortality rate is much less (approximately 6-9/100, 000) because of the more favorable survival of breast cancer in developed region. As a result, breast cancer ranks as the $5^{\text {th }}$ cause of death from cancers overall (458, 000 deaths), but it is still the most frequent cause of cancer in women in both developing $(269,000$ deaths, $12.7 \%$ of total) and developed region, where the estimated number 189, 000 deaths is almost equal to the estimated number of deaths from lung cancer $(188,000$ death $) .^{3}$

INDIAN SCENARIO: In India, the number of deaths due to breast cancer has increased from 48, 170 in 2007 to 50821 in 2010. In India, among older urban registries at Bangalore, Bhopal, Chennai, Delhi and Mumbai, cancer of the lung was the leading site of cancer among males, among females breast was the leading site of cancer. The cancer registries from Aurangabad, Kolkata, Nagpur, Pune and two registries from Kerala also stated that breast is the leading site of cancer among females. ${ }^{4}$

The government records state that the breast cancer cases have almost doubled in the last twenty years. The highest number of breast cancer death was recorded in UP $(8,882)$ followed by Maharashtra (5, 064), Bihar (4, 518), West Bengal $(4,095)$, Andhra Pradesh $(3,863)$ and Rajasthan $(3,097)$.Around 24.8 new cases of breast cancer a year/100, 000 women recorded in Delhi. The figure rose to 32.2 in 2008.5

This study is aimed at understanding which risk factors are important, feasible to tackle and which risk factors would have a great potential as a primary preventive measure.

AIM OF THE STUDY: To study the reproductive risk factors for breast cancer among women attending Tertiary care hospital, Karimnagar, Andhra Pradesh

METHODOLOGY: Study was conducted in Sushrutha cancer hospital, Karimnagar, AP, located two and half kilometer away from Chalmeda Anand Rao Institute of Medical Sciences. IEC approval and permission from the Director of Sushrutha cancer hospital, Karimnagar, was obtained. The study duration was from November 2010 to October 2012. The sample size has been calculated by the method described by Kelsey et al i.e. 100 cases and 200 controls

Informed consent of cases and controls were taken to confirm willingness to participate in the study. Diagnostic criteria for cases was, all the female breast cancer patients, who got diagnosed and conformed by all the three methods namely clinical examination, biopsy finding and expert opinion (On co-Surgeon). Both the cases and controls were taken from the cancer hospital. Healthy female attendants who are taking care of patients in the hospital, both relative as well as non-relative healthy attendants during the interview were taken as controls. Group matching was done with age and sex with the age interval of 5 years.

All the stages of breast cancer and all age group of female, who got diagnosed within 12 months from the date of interview who are willing to participate in the study were included. Cases who got diagnosed more than 12 months from the date of interview were excluded. Information about the exposure were obtained in precisely manner both for cases and controls by using semi structured, pre tested questionnaire with the interview method. Clinical examination was done in the presence of female attendant with adequate privacy.

For testing proforma and feasibility of the study, a pilot study was carried out on 50cases and 100 controls. A predesigned, pretested, semi structured questionnaire was administered to each 
cases and controls. After the pilot study, the required modification was incorporated into the proforma and the data obtained was recollected from the pilot study sample to maintain the uniformity.

The same interviewer has interviewed both the cases and controls for same length of time, using the same pre designed proforma, to check interviewer bias. To minimize the recall bias regarding timing of events, suggestive questions were asked and help of local and national events was also taken to help stimulate the recall. Selection bias was reduced to the maximum extent since clear inclusion and exclusion criteria are defined. All new consecutive cases without any history of prior cancer directed therapy at the time of admission in hospital were included in the study so as to reduced protopathic bias also.

RESULT AND DISCUSSION: For each breast cancer case two healthy controls were matched. Out of 100 cases and 200 controls majority were belongs to the age group of 50-54 years (29\%) followed by 55-59 years group and 45-49 years group. $14 \%$ of study subjects were belongs to age group of more than 60 years. The mean age for cases and controls were $51.92 \pm 6.32$ and $52.77 \pm 7.08$ respectively. (Fig: 1)

Occupation was categorized as daily wages, housewives, private sector and civil servant. It is observed that the majority of cases (68\%) and controls (56\%) were engaged in daily wages including agricultural works, followed by housewives about $20 \%$ of cases and $32.5 \%$ of controls.

The least number of cases (5\%) and controls (1.5\%) were civil servants. Since the study setting was predominantly rural area, majority of study subjects were engaged in agricultural works in terms of daily wages.

It is found that majority of study subjects were illiterate i.e. $78 \%$ of cases and $76 \%$ of controls. And only $22 \%$ of cases and $24 \%$ of controls were literate.

It is observed that $59 \%$ of cases and $39 \%$ of controls were under the group of 'currently separated' which includes unmarried, separated, divorced and widows. It was found that currently separated women were having $2.25(95 \%$ CI 1.38 , 3.67) times risk of developing the breast cancer when compared with currently married women, and the difference between the group was found statistically significant with the p value of 0.001 . (table 1)

Several epidemiological studies have reported that the risk of breast cancer is higher among single women than married women. Fraumena et al $1969^{6}$ stated that the risk of breast cancer was higher among never married women than ever married women in a study on cancer mortality among nuns. Paymaster \& Gangadharan $1972,{ }^{7}$ on Epidemiology of breast cancer in India observed that a relative risk of 3.1 for single women when compared with married women.

Overall among the study subjects (both cases and controls) about $48.6 \%$ of subjects were attained menarche, at less than or equal to 13 years of age and $51.4 \%$ were attained above the age of 13 years. It was observed that the women with early menarche of age less than or equal to 13 years are having $2.55(1.558,4.201)$ times risk of developing the breast cancer when compared to women who attained menarche above 18 years of age. And the difference between the groups was identified statistically significant with the $\mathrm{p}$ value of 0.001 . (table 2)

According to published literature, Early age at menarche has been found to be one of the important determinants in the etiology of breast cancer. Many epidemiological studies like Gao et al $2000^{9}$, McCredie et al 199810, Decarli et al. 1996, ${ }^{11}$ have suggested that the younger a woman's age at 
menarche the higher her risk of breast cancer. Nagata et al 1995, 12 from a meta-analysis of eight case control studies from Japan reported an Odds Ratio of 0.7 (95\% CI 0.6-0.8) for women with onset of menstruation after age 16 compared to those before age 14 years.

The table 3 depicts the distribution and association of parity status of study subjects with the risk of developing breast cancer. It was observed that $12 \%$ of cases and $4 \%$ of controls were nulliparous and the risk of developing breast cancer is $3.273(1.29,8.29)$ times more in nulliparous women when compared with parous women. And it is proved statistically that there is difference between the group exist.

Through review of literature it was observed that parity has significant role in causing breast cancer. In a meta-analysis of three cohort and five case control study from the Nordic countries, Ewertz et al 199013, found that nulliparous women had 30\% higher risk of breast cancer compared with parous women and the risk reduced by about $16 \%$ for every two births.

Whereas Rao et al 1994, ${ }^{14}$ reported that a 40-50\% reduction in the risk among multiparous women with 3 or more pregnancies compared to nulliparous women. Magnusson et al 199915, found a strong trend of decreasing breast cancer risk with increasing parity (OR 0.85; 95\% CI 0.80-0.90) per borne child was observed in women aged between 50 and 74 years.

In a nationwide cohort study of women with at least 5 births (grand multiparas) conducted in Finland, Hinkula et al 200216, found that parity of fifth child onwards was an independent and powerful protective factor for breast cancer risk.

Nagata et al 1995,12 from a meta-analysis found that parous women with 3 or more births had a $32 \%$ diminished risk (OR 0.7; 95\% CI 0.5-0.9) compared with nulliparous women, independent of age at first child birth.

Table 4, explains the distribution and association of breast feeding with the risk of developing breast cancer. It shows about $7.7 \%$ of total study subjects were not exposed to breastfeeding practice and the proportion of women with no breastfed is more in cases when compared with controls. And they had $3.45(1.44,8.28)$ times more risk of developing breast cancer when compared with women who breastfed their babies. It is proved statistically that there is significant difference exist between the groups.

Similar reports were stated by several authors in their studies. For example Romieu et al 1996,17 from a case control study found that parous women who had never lactated had a reduction in breast cancer risk (age adjusted OR 0.39; 95\% CI 0.25-0.62) compared with parous women who had never breastfed.

From a population based case control study, Lubin et al 1982,18 found, breast feeding to be apparent protective factor for the risk of breast cancer independent of age at first birth and parity.

Yoo et al 1992,19 also made a similar observation that the risk was lowest among premenopausal women who had ever lactated for 7-9 months (adj. OR 0.39; 95\% CI 0.15-0.97) compared with parous women who had never breastfed.

McCredie et al 1998,10 stated that breast cancer risk tended to fall amongst parous women with increasing duration of breastfeeding and the association was most apparent in the youngest women, while women over 40 years at diagnosis showed no clear negative trend.

Vidyashankar 2002,20 in his study among 200 breast cancer cases, observed that breast feeding for less than 3 months was a risk factor for breast cancer and that was present in only $4.5 \%$ of the patients, while $75 \%$ had breastfed their children for more than 2 years. 
LIMITATION: Despite all the efforts of the investigator certain limitations remained uncontrolled. Because of the retrospective nature of the study, certain types of biases are bound to creep into the study. Every attempt was made in the design and in the analysis, to minimize the various types of biases like berksonian bias, recall bias and protopathic bias.

\begin{tabular}{|c|c|c|c|c|}
\hline Marital status & Cases & Controls & Total & $\begin{array}{c}\text { OR } \\
(95 \% \mathrm{CI})\end{array}$ \\
\hline $\begin{array}{l}\text { Currently separated } \\
\text { (unmarried/divorced/widows) }\end{array}$ & $59(59)$ & $78(39)$ & $137(45.6)$ & \multirow{3}{*}{$\begin{array}{c}2.25 \\
(1.38,3.67)\end{array}$} \\
\hline Currently married & $41(41)$ & $122(61)$ & $163(54.4)$ & \\
\hline Total & $100(100)$ & $200(100)$ & $300(100)$ & \\
\hline
\end{tabular}

Table 1: Distribution and Association of marital status with breast cancer

$\mathrm{X}^{2}=10.75 ; \mathrm{p}$ value $=0.001$

\begin{tabular}{|c|c|c|c|c|}
\hline \multicolumn{1}{|c|}{ Age at menarche } & Cases & Controls & Total & $\begin{array}{c}\text { OR } \\
\text { (95\% CI) }\end{array}$ \\
\hline Less than/equal to 13 years & $64(64)$ & $82(41)$ & $146(48.6)$ & \multirow{2}{*}{$2.55(1.558,4.201)$} \\
\hline More than 13 years & $36(36)$ & $118(59)$ & $154(51.4)$ & \\
\cline { 1 - 4 } Total & $\mathbf{1 0 0 ( 1 0 0 )}$ & $\mathbf{2 0 0 ( 1 0 0 )}$ & $\mathbf{3 0 0 ( 1 0 0 )}$ & \\
\cline { 1 - 3 } & &
\end{tabular}

Table 2: Distribution and Association of early age at menarche with breast cancer

$\mathrm{X}^{2}$ value 14.12; $\mathrm{p}$ value 0.0001

\begin{tabular}{|c|c|c|c|c|}
\hline Parity & Cases & Controls & Total & $\begin{array}{c}\text { OR } \\
(95 \% \mathrm{CI})\end{array}$ \\
\hline Nulli parous & $12(12)$ & $8(4)$ & $20(6.4)$ & \multirow{3}{*}{$\begin{array}{c}3.273 \\
(1.29,8.29)\end{array}$} \\
\hline Parous & $88(88)$ & $192(96)$ & $280(93.3)$ & \\
\hline Total & $100(100)$ & $200(100)$ & $300(100)$ & \\
\hline
\end{tabular}

Table 3: Distribution of association of parity with breast cancer risk

$\mathrm{X}^{2}$ value $=6.857 ; \mathrm{p}$ value $=0.008$

\begin{tabular}{|c|c|c|c|c|}
\hline Breastfeeding & Cases & Controls & Total & $\begin{array}{c}\text { OR } \\
(\mathbf{9 5 \%} \text { CI) }\end{array}$ \\
\hline Absent & $14(14)$ & $9(4.5)$ & $23(7.7)$ & \multirow{2}{*}{3.45} \\
\cline { 1 - 3 } Present & $86(86)$ & $191(95.5)$ & $277(92.3)$ & $(1.44,8.28)$ \\
\hline Total & $\mathbf{1 0 0}(100)$ & $\mathbf{2 0 0}(100)$ & $\mathbf{3 0 0}(\mathbf{1 0 0})$ & \\
\cline { 1 - 2 } & &
\end{tabular}

Table 4: Distribution and association of breastfeeding with breast cancer risk

$\mathrm{X}^{2}$ value $=8.499 ; \mathrm{p}$ value 0.0035 


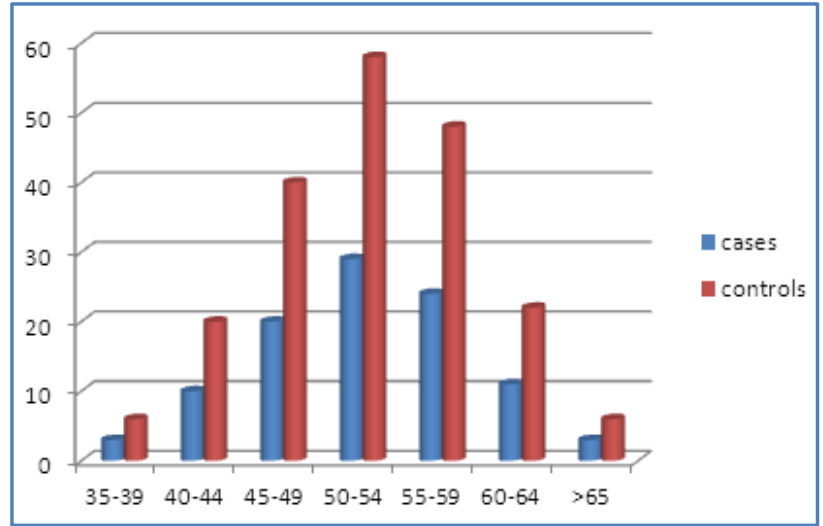

Figure 1: Age wise distribution of study sample

CONCLUSION: It was found that the risk of developing breast cancer was statistically significant for the factors like marital status, parity, age at menarche and breastfeeding and the present study was an attempt to identify risk factors and to quantify the strength of their association so as to help eliminate gaps in knowledge and barriers regarding risk factors for breast cancer and to know which risk factors are important, feasible to tackle and preventable which would have a great potential as a primary prevention measure. It would suggest further research non-identified factors at its genome level for better understanding.

\section{REFERENCES:}

1. Harrison's Principles of Internal Medicine, $18^{\text {th }}$ Edition.

2. Parkin DM, Whelan SL, Ferlay J, Teppo L and Thomas DB (eds) (2002): Cancer incidence in five continents, Vol. VIII, IARC Sc. Publns No.155, Lyon.

3. Globancon cancer face sheet 2008 Retrieved on 06-08-2011.

4. NCRP (2006-2008): National Cancer Registry Programme. Two-year report of the populationbased cancer registries 2006-2008, ICMR, New Delhi, India.

5. Women and cancer data/health statistics. Available at www.developmentchannel.org.

6. Fraumeni JF Jr, L Loyd JW, Smith EM, Wagoner JK. Cancer mortality among nuns: role of marital status in etiology of neoplastic disease in women. J Natl Cancer Inst 1969; 42:455-468.

7. Paymaster JC and Gangadharan P. Epidemiology of breast cancer in India. J Natl Cancer Inst 1972; 48: 1021-1024.

8. Brignone G, Cusimano R, Dardanoni G, Gugliuzza M, Lanzarone F, Scibilia V and Dardanoni L. A case - control study on breast cancer risk factors in a Southern European population. Int J Epidemiol 1987; 16: 356-361.

9. Gao Y-T, Shu X-O, Dai Q, Potter JD, Brinton LA, Wen W, Sellers TA, Kushi LH, Ruan Z, Bostick RM, Jin $\mathrm{F}$ and Zheng W. Association of menstrual and reproductive factors with breast cancer risk: Results from the Shanghai Breast Cancer Study. Int J Cancer 2000; 87: 295-300.

10. McCredie M, Paul C, Skegg DCG and Williams S. Reproductive factors and breast cancer in New Zealand. Int J Cancer 1998; 76: 182-188. 
11. Decarli A, LaVecchia C, Negri E and Franceschi S. Age at any birth and breast cancer in Italy. Int J Cancer 1996; 67: 187-189.

12. Nagata $\mathrm{C}, \mathrm{Hu} \mathrm{YH}$ and Shimizu H. Effects of menstrual and reproductive factors on the risk of breast cancer: Meta-analysis of the case-control studies in Japan. Jpn J Cancer Res 1995; 86: 910-915.

13. Ewertz M, Duffy SW, Adami H-O, Kvale G, Lund E, Meirik O, Mellemgaard A, Soini I and Tulinius $\mathrm{H}$. Age at first birth, parity and risk of breast cancer: a meta-analysis of 8 studies from the Nordic Countries. Int J Cancer 1990; 46: 597-603.

14. Rao DN, Ganesh B and Desai PB. Role of reproductive factors in breast cancer in a low risk area: a case control study. Br J Cancer 1994; 70: 129-132.

15. Magnusson CM, Persson IR, Baron JA, Ekbom A, Bergstrom R and Adami H-O. The role of reproductive factors and use of oral contraceptives in the aetiology of breast cancer in women aged 50 to 74 years. Int J Cancer 1999; 80: 231-236.

16. Hinkula M, Pukkala E, Kyyronen P and Kauppila A. Grand multiparity and the risk of breast cancer: Population-based study in Finland. Cancer Causes and Control 2001; 12: 491-500.

17. Romieu I, Hernandez -Avila M, Lazcano E, Lopez L and Romero-Jaime R. Breast cancer and lactation history in Mexican women. Am J Epidemiol 1996; 143: 543-552

18. Lubin JH, Burns PE, Blot WJ, Lees AW, May C, Morris LE and Fraumeni JF Jr. Risk factors for breast cancer in women in northern Alberta, Canada as related to age at diagnosis. J Natl Cancer Inst 1982; 68: 211-217.

19. Yoo KY, Tajima K, Kuroishi T, Hirose K, Yoshida M, Miura S and Murai H. Independent protective effect of lactation against breast cancer: A case control study in Japan. Am J Epidemiol 1992; 135: $726-733$.

20. Vidyashankar. Western' risk factors for breast cancer do not seem to hold in India. Journal of Indian Medical Association, 2002 June; 100; 282-287.

\section{AUTHORS:}

1. Kannan Krishnamoorthy

2. Gopal Rao Jogdand

3. Yennam Naresh

\section{PARTICULARS OF CONTRIBUTORS:}

1. Assistant Professor, Department of Community Medicine, Chalmeda Ananda Rao Institute of Medical Sciences, Karimnagar, A.P.

2. Professor and HOD, Department of SPM, Chalmeda Ananda Rao Institute of Medical Sciences, Karimnagar, A. P.

3. Final Year Student, Department of Community Medicine, Chalmeda Ananda Rao Institute of Medical Sciences, Karimnagar, A.P.

\section{NAME ADDRESS EMAIL ID OF THE CORRESPONDING AUTHOR:}

Dr. Kannan Krishnamoorthy, \#43, Mariamman Koil Street, Kathir Kamam, Pondy - 9.

E-mail: drkannan83@gmail.com

Date of Submission: 11/02/2014.

Date of Peer Review: 12/02/2014.

Date of Acceptance: 01/03/2014.

Date of Publishing: 20/03/2014. 